\title{
Index
}

Note: 'n.' following a page reference indicates the number of a note on that page.

advertisement 25, 30, 71-2, 82, 85, 93-6,

$98,100-2,120-3,126,132$, $168,173-4,188,198,223,284$ 288

aimed at young housewives 85

and generation cohort 25

early women's 39,89 n. 50

employing known actresses 85

television 80, 97

Tennent girls 100, 124

Tennent's beer cans 96

unisex 175

using middle-class women 84

women playing darts in public bars 85

alcopops see youth drinking

All Bar One 135, 157-9, 163n.37, 167, 172,282

American imported beer 96

aperitifs 80, 108, 196

baby boomers 173

Babycham see female beverages

Bacardi 101, 122, 139

Breezer 170, 198, 280

Ballantine 101

beer consumption

growth 1959-79 102

promotion by Project Eve 124

beer hawking 272n.60

Beer Orders 12n.29, 164

and traditional masculine culture 164

as promotor of change 187 exaggerated impact of 167

impact on drinking habits 165

beerhouses 19-20, 24-5

and northern cities 23

and respectable northern women 23

bans on women 23

clientele 23

history of 14,22

historical confusion 23

in Bolton 23

in Edwardian Salford 12n.29, 23

in York 23, 27

origins of 14

Wine and Beerhouse Act (1869) 14

Belgian beers 179-80, 185, 287

see also style bars

Bierodrome chain 178-9, 181

billiards rooms 20, 41

binge drinking 26, 189, 198-9, 201, 207-8, 210, 231, 266-7, 292

see also youth drinking

bingo clubs 92

Boddington's 'Cream of Manchester' campaign 174

Booth, Charles 242, 247

bottled beers 5, 76-9, 83, 125, 170, 179, 182, 197, 207, 223-4, 227

bouncers 114

bourbon 199

Brand, Christianna 57

branded

divisions 159 
glassware 124, 181, 287

images 159

brands 39, 73, 79-80, 96, 98, 117, 140, $158,172,175,180,183,206$, 287

Brewers' Society 54, 62, 73, 75, 85, 102, 138, 296, 299-300

Bunge, Professor Gustav von as source of Edwardian moral panic 244

expert on breast feeding and infant deaths 244

burgundies 82

Burnett, John 17, 142

see also lager, and cold drinks revolution

Butler, W. Waters (Mitchells \& Butlers), Progressive brewer 19, 223, 225, 298

advocated industry's nationalization 3 environmentalism of 224, 231, 290 hated drunkenness 218, 222, 227 improved pubs reduced drunkenness 224

Progressive traits of 290 saw food as antidote to drunkenness 3, 226

social conscience of 229

sought sobriety 229, 257

transformed into Progressive 229, 257, 277, 290

wanted respectable women as patrons 257, 277

women viewed as deterrents to drunkenness 229

café bars 199

Campari see female beverages

CAMRA 77-8, 100, 118, 122-3

Capstick, Sheila 116

Carlisle 226, 229-30, 253, 255, 257

CCTVs 152

Central Control Board 37, 219, 221, 225, 277, 290, 296, 300

see also D'Abernon, Lord

chameleon bars 159, 203

champagne 181 childrearing 213

children's play areas 284

cider 14, 39, 80, 83, 94, 104-5, 109, $130,139,174,185,196-7$, 206, 210, 264

cigarettes 256, 260

cinemas 194

Cinzano 102

clarets 82

Clore, Charles 74

clubs 71, 188, 194, 197, 205-6, 209, 211

cocktails 5, 148, 158, 172, 183, 196, 198-200, 262, 282

coffee 91, 154, 158-9, 170, 179-80, $183-4,187,282,292$

cognac 101

Cohen, Stanley 238, 247

Committee for Verse and Prose Recitation 37

companionate marriages 2, 70, 80, 122

Cooper, Derek, wine expert 136-7

Coors Brewers see beer sales, Project Eve corporate social responsibility 175-8, 205, 291

cruover 136

D'Abernon, Lord (Chairman of Central Control Board) 219, 221, 229, 277

darts 39-41, 64, 85, 116-17, 185, 264

Davis, Ben 99, 146, 158, 286 as homophobic commentator 147 influenced pub design 147 perpetuated masculine culture in pubs 146

Dickens, Charles 2, 15-16

DiSaronno 121

subverted gender stereotypes 175

drink environment role of bar staff in attracting women 150

drinking habits abstension from alcohol 26, 65, 279

adolescent 211, 261-5

and changes in 252

and class, dating and improved pubs 28 
and demographic changes 131, 166 and economic changes 166 emergence of the 'local' 52, 54, 67 and ethnic minorities 172, 213 and family leisure 103, 183, 284 and 'genderquake' 211 and life cycle 211 and masculinity in Scotland 119 and pub meals 169 and socializing 104, 108-9 and racial discrimination 116 and repertoire drinkers 198 and working-class norms 106 at home 139, 189

causes of women's rising consumption 211

changed by work outside home 284 changes in 178, 252, 283 changes in World War I 252, 256 changes in World War II 52-3, 56-63, 256, 258, 260-1

class and age 159

class and pubbing 15,108

domestic consumption 117, 139, 189 gender differences 117, 177, 179, 182 globalization of 131, 180 growing women's pub patronage 169 , 252

impact of Beer Orders 160, 286

impact of deindustrialisation 285

impact of government legislation 286 impact of wine bars 187

importance of gender 79, 183

influx into licensed premises in world wars 53,252

see also Tim Martin

interwar emergence of new 32

middle-class norms 20, 106-9

new consumer taste 85

new demographic trends 124

new in London 21

new subculture of drinking in pubs 150

new women's 139

revolution in 280

Scottish women 58

segmented markets 196, 158 shaped by class 104

shaped by class and age 109

shaped by generation $\mathrm{Y}$ women 175

shaped by geography 119, 212, 283

shaped by life cycle, class and age 76

stigma against women 211

trends in 277

Tyneside 285

unescorted women 285

unisex drinking habits 180, 182

village patterns 212

drinking venues 172

revolutionized by youth drinkers 204

types of 171

drugs 194-9, 208-9

eating out 188, 278

see also food

Egon Ronay's 137-8

El Vino's 64

Eldridge Pope 138

Ellwood, Iain (Interbrand) 148, 157, 173

environmental cues 148

research on built environment 148

environmental psychology 150, 187

and colours, décor, designs and furnishings $147-8,200$

and consumption 149

and customers' reactions 148

and female-friendly venues 149, 283

and women's antipathy to traditional pubs 148

Equal Rights in Clubs Campaign for Action (ERICCA) 116

escorts (for women) 18, 93, 108-9, 255-6

and advertisements $72,84-5$

and lesbian bars 184

and prostitution 18-19

during World War I 251, 255

during World War II 52-3, 55, 59-60, 62-3, 259

for bingo clubs 92n.85, 92, 265

in 1980s 92, 283, 285

interwar era 26, 31n.106-7, 114-15, 283

see also unescorted women 
FABS (flavoured alcoholic beverages)

$$
\text { 197-8, 280-1 }
$$

female beverages 181-2, 207

Animee 126

Babycham 80, 101, 207, 210

Bailey's 174, 207

Bleu de Brasserie 120

Bloody Mary 91

Campari 80, 108

Cherry B 210

Cutty Sark 101

gin $71,172,181,199$

gin-and-tonic 80

introduced by Coors 125

lager and lime 120

liqueurs 108, 198, 207

Mackeson's stout 39, 72-3

Malibu 207

Miller Pilsner 120

Organic Honey Dew (Fuller's)

$$
\text { 129n. } 54
$$

Pimm's 80, 101

port $80,231,264$

port-and-lemon 80, 264

Red Biddy 82

RTDs (Ready to Drink) 122, 182, 198, 280, 282

shandy (beer and lemonade) 80, 182, 264

sherry $71,80,91,93-4,280-2$

Taboo 207

Tequila Sunrise 207

Tia Maria 207

vodka 101-2, 172, 181, 196, 199, 210

young and middle-aged women consumption of 83

see also cider; cocktails; DiSaronno;

FABS; imported beers; lager; soft drinks; wine

female licensee 98, 168-9

and widow's year 99

linked with women in workforce 169

female-friendly venues $114,155,157,160$, $168,185,282,286$

and market segmentation 171

impact of 158

profitability of 159
Fetzer Vineyards 177

see also Martin, Tim

films

post-1945 emphasis on domesticity 71

fish and chips customers 41

Fisher, Fiona 16, 21

food 28, 103, 114, 122, 142, 154, 158, 165, $170,175,177,183,189,231$, 282, 292, 294n.15, 299

football supporters 105

friendly societies 19 see also working-men's social clubs

Fullers

and Fine Line venues 159

London Pride 120

Gallo, E \& J 138, 140

gastro pubs 170, 280, 282

gender boundaries

redefined in youth drinking 206

shifting in World War II 59, 63, 256, 260

subverted by raves and dance clubs 195

subverted by wine bars and pubcos 168

gender difference 117, 126, 179, 207-8, 282, 289

gender roles 167, 285

gender stereotypes 175

gender-neutral drinking spaces

World War II 58

generation X 25, 173-5

generation Y 25, 173, 175-6, 178-80, 207, 287

gentlemen's clubs 171

private (sex) clubs 17, 99, 114, 141, 171

Gilbey, W. \& A. 137

gin and-tonic 80

craze 267

palaces 16

Girouard, Mark 18, 20

glasses 82, 125, 129

and appealing to women 124

and sexism 125

Gleiss, Barbara 7, 47n.48, 49n.84, 50n.93 
Gourvish, Terry 6, 22, 24, 27, 31, 33, 102

greater gender equality 115

Green for Danger 57

Guinness 32, 39, 55, 71-3, 85, 97-8, 174, 298

and emancipated advertising 112

as pioneer of market research 110

promotion of darts 85

reversal of gender roles in commercials 112

women used in advertising 73

Hammond's United Brewery 93

happy hours 152

Hartlepool

banned women drinking alcohol 253

heavy drinking

posh pubs 107

Heneky Bars 135

Hennessy advertisements 101

homosexuals 146-7, 201, 209, 229

lesbian bars 184-5

see also Davis, Ben

Hooper's Hooch see youth drinking

hybrid pub, restaurant and coffee house 154, 160, 170, 207

Hyde, Neal (Manchester brewer) 77-8, 82

imported beers 124, 172, 180-1, 188, 287

Hoegaarden and Leffe 180

trend in food consumption 180

Incorporated Brewers' Guild 100

interwar drinking surveys 7, 32-3

Bolton 24-5

London 29-30, 48nn70-1

Ernest Selley 31-2

York 27-8

interwar improved pubs 18, 23, 34, 152, $157,223,232,284$

appealed to respectable women 27 , 30-1, 36

feminized décor in 24

food in 19, 28

generated wider female clientele 41

location of 34 numbers in London 30

philosophy 21

transformed women's drinking 24

see also Progressives; Progressive brewers, and the lounge

Jacob's Creek 140

jug and bottle compartment 17, 20

jukebox music 117

juvenile

delinquency 263

drinking 261-2

drunkenness 264

keg beers $71,77-80,85,88 \mathrm{n} .43$

ladies' bars 277

and respectable women 21-2

gendered drinking space of 22

interwar disappearance of 37

lager 71, 85, 129, 142, 174, 185, 195,

206, 210

advertised as women's drink 82

and cold drinks revolution 83

and new dietary habits 83

as youth beverage 194

attractions of 83

Barclay's early production of 83

Carlsberg Draught 182

consumption 83

Double Diamond 80

early women's advertisement 81

Grolsch 196

Harp 98

Heineken 97

Holsten Pils 196

ice 197

introduction of 82

louts 265,280

premium lagers 207

refrigerated 83

sales in Scotland 83

served in special glasses 82

Skol 80, 82

lager lovelies 95

Langhamer, Claire 22, 51n.109, 55-7, $60-1,76,264$ 
late-night licences 202

legislation

catalsyt of changes in women's drinking 286

Children's Act (1908) 11n.14, 248

Employment Protection Act 131

Equal Pay Act 131

Friendly Societies Act (1974) 115

liberalized licensing laws 200-1, 230

licensing acts

(1921) 228, 257

(2003) 267

Race Relations Act, 116

Street Offences Act (1959) 265

Sex Discrimination Act (1975) 115, 131,171

Wine and Beerhouse Act (1869) 14

licensed premises

and sports 19

licences for restaurants and hotels 103

'Local', the

origins of 66n.5

Loftus, Simon 141, 229

London's East End

and drinking 20

long pull 228, 236n.31

Lorac, E.C.R. 55

lounge 24-8, 30, 33, 37, 39-41, 58,

72-3, 82, 84-5, 92, 103, 114, $212,260,292$

advertising unescorted women 1950s, 72

and décor 21

and encoded messages 21

and new interwar drinking habits 24

and respectability $20-1$

and socialising by both sexes 24

bars 114

ladies 91

middle-class norms in 24

socability in 21

lower-middle classes

embraced respectability 21

\section{McCall's 101}

Mackeson's stout see female beverages

Madonna 174 male subculture of drinking

changes in 1980s 114

Market Information Services

1949 survey 55, 62, 65, 72

market research 65, 96, 155, 182, 186-7

identifying women as early adopters 139

importance of women as consumers 139

role of physical environment in sales 149

sales of wines in pubs 141

survey in 1956-57 73

market segmentation 109, 152, 229

marketing

products 173

psychology 79

surveys 25

Markham, Violet 54

Martin, Tim 153, 175, 218, 283, 286

and banning of smoking in pubs 152

and corporate social responsibility (CSR) 176-8

and layout of pubs 152

and smoking 176

as interwar Progressives 152

background of 150

business philosophy 152, 177

founding father of modern pub 155

influences on 176, 291

innovator 155

outsider to drink industry 290

parallel with Progressive brewers 151, 291

sense of social responsibility 291

smoking 177

sought more women as customers 152

undermined masculine drinking culture 292

understanding of women's attitudes 292

widen pub clientele 291

masculine culture

challenged during World War II 58

changed with keg beer 71, 79

in Bass advertising 111 
in north 23

lacked toliets 21,36

misogynism 106

norms of 84

resistance to change 289

rough working-class 105

shrinking numbers of pubs 282

transformed by pub improvement 42

Mass-Observation 24, 32, 52-6, 58-9, 60-1, 63, 71, 258, 264-6, 300

and unreliable statistics 26

Bolton's statistics 23

impressionistic evidence 24

survey in 194762

Matchbar 183

chain of bars aimed at women 148

Measham, Fiona 267

'men-only' drinking bars 25

outlawed 286

persistence in Bass pubs 111

middle-class drinkers 109

and new drinking habits 21

as pub drinkers $107-8$

married 108

see also drinking habits

Middlesbrough 253, 255-6

mixologists 172

moral panics 242

adolescents in World War II 261

and alcopops 267

and binge drinking 266-7

and Central Control Board 251

and defective motherhood 241

and flappers 256

and infant mortality 240, 241

drinking, World War I and Lloyd George 250

Edwardian England 238-48

elite driven 252, 258, 267

emergence of new critique of alcohol 244

female drinking and Boer War 241

fostered by scholars 266

grass roots 239, 267

in 1950s 265, 271n.52, 279

influx of women into licensed

premises in World War I 252 interest group 266-7

over breast feeding and infant deaths 243

over recruitment of soldiers 239

rising female drunkenness 242

traits of 238

World War I 248-57

World War II 258-64

Moss, Stella 12n.32, 17-8, 22-3, 34, 36, 49 n. 81

motor cars 39, 83

Murphy's beer 121

national advertising campaign targeting women as drinkers

(1948) 72

(1960) 75, 82-3

(1970s) 93

Nevile, Sydney O. (Whitbread \& Co.), Progressive brewer 18, 19, 21, $37,54,228,233,257,278$, 292, 297

advocated nationalization 3

and environmentalism 5, 220, 224, 227, 231

and transnational progressivism 291 attracting respectable women 18,277 class and pub improvement 34 leader of Progressive brewers 3 loathed drunkenness 222 motivated by pride 35

need for improved working-class pubs 33-4

promoted sobriety 223, 226

social conscience of 222, 290

sought government intervention 223, 225

supported scientific study of drunkenness 223, 226, 232-3, 237

n. 55

wanted to expand the pub's clientele 224, 229

new alcoholic beverage

Stud 102

new drinkers

middle and upper classes in 1970s

102 
New Labour 201, 205, 230

New World wines 139-40, 280

Nicholls, James 53

Nicholson, B.D. 24, 30, 32, 48nn.70-1

night clubs 194, 201-3, 208-9

Nottingham 200

off-licences 109

Old World wines 139-40

Orwell, George 151

perpendicular drinking 16, 29-30, 231

Pimm's 80101

Pitcher \& Piano 118, 135, 155, 159, 202, 286

and consumer research 156

background of staff 156

female friendly 283

female-friendly environment 156

importance of toilet hygiene 156

prototype of female-friendly venues 157

success of 157

see also Tweddle, Crispin

Playboy

Bunnies 96

Club 96

pornography $93,106-7$

poverty-stricken women

and drinking habits 20

PPS (premium packaged spirits) 159, 174,280

premium beers

Belgian beers 125

in bottles 125, 197

in branded glasses 125

packaged beers 170

unisex appeal 125

private bars $20-1$

Progressives

and food sales 19

beliefs of 35

characteristics of 18-19, 226

environmentalism of 19, 21

philosophy 19, 21, 230

types of 18

Progressive brewers 17, 21, 24, 31, 36,
$42,160,218,220,222,225$,

232, 284, 291

and big breweries 223

and changes in cultures of drinking 24, 34, 40, 290

and drunkenness 222, 228

and environmentalism 36, 220, 226, 232, 290

and improved slum pubs 34, 49n.84 and moral uplift 2, 8, 19, 22, 26, 36, 228, 278, 290, 293n.2

and more women drinkers 277

and the lounge 24

and toilets 36

and women's humanising role 227

appealed to respectable women 27 , $30-1,36$

as socially responsible businessmen $222,228,233$

attracting diverse patrons 229

family sociability 20

food as antidote to drunkenness 227

gender equality in drinking 221

impact of World War I 257

improved pubs 18, 23, 34, 36, 152, 157, 223, 232, 284, 290

introduced lounge for women 227

layout of drink premises 231

motivation of 35,290

new drinking norms 221

opposed cut-throat competition 224

promoted lower alcoholic beers 229 , 257

reform agenda 227

restrained drinking 224

role of example setting 229

role of women drinkers 221

scientific approach to drinking 220 , 223

sought respectable patrons 224

traits of 221, 223, 225-6, 232, 290

see also public house improvement

Project Eve 125

proportion of women drinkers

methodological problems in estimating 32 
prostitutes 16, 17-19, 24, 59, 62, 65, $105-7,132,149,249,256$, $259,265,279,285,288-9$

psychology of retailing $120,178-9$ importance of colours 148 pub interiors and layouts changes in layouts 103-4, 283 changed physical layout in 1970s 146 revolution in 158

pub sports $71,106,121$ snooker 116-17 pubcos $150,154,158,164-8,176,183$, $187-8$

new career paths for women 165 public bars 18-21, 24, 28, 30, 40, 58-9, $62,79,85,299$

and male behaviour 24

elimination of 103

entry of women in World War II 59 public house improvement 19, 36, 277 and women's toilets 24 assault on masculine culture of drinking 41

cost of 24

extent of 41

feminized décor in 24

food in 19, 28

fragmenting pub culture 31

generated wider female clientele 41

location of 34

numbers in London 30

wider women's patronage 29

publicans

importance of class background 141

real ales 287

see also CAMRA

respectability $18,20-1,229$

and age 19

and counter screens 16

and jug and bottle drinking 16

and public drinking 18

and slums 19

and women in vaults 17

bar to respectable women 23

changes in drinking habits 23

dominant code of 15 drinking in early 19th century and 45

differing historical interpretations of $45 n .27$

in northern cities 37

ladies versus women 43n.12

withdrawal from public drinking 15

working-class pubs and 106

see also gin palaces

restaurants 141, 150, 170, 184

Rowntree, B. Seebohm 23, 27-8, 32, 65, 239, 241-3

rugby 121,270

rum $101,172,181,199$

saloon bars 18, 20-1, 24, 37, 58-9, 72, $84-5,277$

Sandar, Sir Edgar 102

Sarsfield, Maureen 55

SASSY 174

Selley, Ernest 23-4, 30-2

shots and shooters see style bars

Showerings 101

sale of small wine bottles 143n.26

see also Babycham

Sims, George R., social reformer and journalist

campaign against maternal drinking 245

"The Cry of the Children" 245

Smirnoff

Ice 122, 182, 198, 280, 282

Red Vodka 181

Vodka 101-2

Smith, Michael A., sociologist

pub typology 104

smoking ban 177,185

snack manufacturers 96, 122

soft drinks 109, 170, 181, 196

speciality imported beers $158,172,180$, 287

Hoegaarden and Leffe 181

spirits 101, 139, 197, 201, 210, 261, 280

standardization 71

and keg beers 77

stout $71-3,76$

Stowells of Chelsea 137, 140

style bars(also called concept bars or 
pre-club venues) 172,180 , 188, 207, 211, 283-4

and generation $\mathrm{Y}$ women 179

and night-time economy 199

and psychology of sales 287

and shots and shooters 172

and unisex drinking habits 180

bottled beers and women 181

chameleon philosophy 184

educational role 178

emergence of 25

layouts 200

perpetuated masculine culture 173

premium beers 117

sales of imported beers 181

shaped by generation $\mathrm{Y}$ women 175

supermarkets 109, 130, 138, 140-1, 178, 218, 280

Sykes, Melanie 175

\section{Taylor Walker}

and darts league, 85

Tetley 120

tied houses 14-15, 27, 137, 141-2, 160,

$$
164-5,167
$$

and pub improvement 49

Timothy Taylor 174

toilets 75, 117-19, 127n.16, 131, 133, 151, 153, 155, 158, 165, 183, 200, 286

deplorable condition in 1960s 74

high standards and women drinking 74

importance of 284

in style bars 284

trade unions 19

Tweddle, Crispin 150, 155, 286

see also Pitcher \& Piano

Tyneside pubs 105

typology of pub types 104

unescorted women 19, 91-2, 184, 259

and bingo clubs 92

in World War II pubs 59, 62

older and elderly 31

Varlett, Claire 165 village pubs 212

waitress service 133

Walton, John, historian 41

wartime-film making 53

Wetherspoon, J.D. 118, 158, 189, 199, 201-2, 282-3

and family socability 151

and toilet hygiene 151, 153

appeal to women 176

as female-friendly pubco 153

embraced environmentalism 151

High Street presence 154

retail philosophy of 151

role of gardens 151

see also Martin, Tim

wine 80, 83, 109, 124, 130, 137-9, 167, 170, 181, 198, 200, 210

appealed to both sexes 26

French 133

off-licences sales 139

rising consumption 109

socializing patterns 109

supermarket sales 139

wine bars 17, 103, 109, 119, 124, 132, $141-2,146-7,155,157,165$, $171,185,280,283,289$

attractions to women 132-3

catalysts to expansion 131

chains of 135

class status of 133

feminized atmosphere in 132

gender neutral space in 133

growth of 134

Horace Rumpole's 136

in London 132, 134

influence on pub design 147

lacked draught beer 132

new subculture of drinking 132

numbers of 143

objections to licensing 136

ownership of 135

popular with single women 135

promoted by legislation 131

proprietors of 135

redefined gender boundaries 132

revolution in (1975-85) 130, 289 
slow growth of 130

slow growth of meals in 134

targeted clientele of 132-3, 171

women

abstainers 280

and drinking in Lancashire textile districts 32

and public drinking spaces 19

as brewsters 100

as catalysts of change 292

as cocktail managers 172

as dart players 39

as retailers 184

as tenants 168-9

avoidance of licensed premises (post1945) $64,73,92$

behaviour shaped by cultural rhetoric 73

dislike of pubs 155

exaggerated numbers in World War

II licensed houses 60-1

excluded from Scottish bars 32

exclusion from northern miners' pubs 32

executives 185

higher disposal income 284

increased pub patronage in World Wars I and II 57, 252, 272n.72

licensed outlets 59

working-men's clubs $37,78,115,117$, $131,155,285-6$

declining popularity of $116-17$

formation of clubs and institute union 71

men-only policy 116

playing of tombola 71

racial discrimination in 116

women admitted as wives $127 \mathrm{n} .10$

Yates Wine Lodges 135

young women

first entering World War II pubs 56

improved pubs as a draw in World War II 58 youth drinking alcopops 152, 196, 198, 210, 265-7

and bouncers and door pickers 204

and circuits 202, 205-6

and class 207, 209

and clubs 22, 195-6, 200, 211, 265

and designer drinks 196, 203-4

and drink manufacturers 196

and drugs 195-7, 200, 202, 209

and ethnic minorities 212

and Hooper's Hooch 196-7, 207

and longer licensing hours 201

and raves 195-6, 201-2

and shooters and slammers 197-8

changes in city centres 201

dancing and raves 195

'decade of dance' 195, 199

drugs 195

Flavours for Ravers 196

fostered by drink manufacturers 213

impact of drink outlet design 199

in villages 212

interpretations of 210

ladettes 200

lager louts 200, 265

liberalised licensing hours

mobility 205

'new culture of intoxication' 199

new dance subculture 195

new subculture 194, 199, 204

night-time economy 200, 203

pre-loading 209

pushing sales 201

recreational drug war 196

redesigned gender roles 205

segmented markets 202

smart, 'buzz' or energy drinks 198

strong alcoholic beverages 206

subcultures of 208

swig culture 202

traits of 205

see also binge drinking

Zweig, Professor Ferdynand 71, 104 